\title{
INCIDÊNCIA E SEVERIDADE DA MALFORMAÇÃO FLORAL EM SEIS CULTIVARES DE MANGUEIRA ${ }^{1}$
}

\author{
NILMA OLIVEIRA DIAS ${ }^{2}$, MARIANA TEXEIRA RODRIGUES VILA ${ }^{2}$, ANSELMO ELOY VIANA ${ }^{3}$, TIYOKO NAIR HOJO \\ REBOUÇAS ${ }^{3}$, ABEL REBOUÇAS SÃO JOSÉ3, MARIA APARECIDA CASTELLANI BOARETTO3 ${ }^{3}$, MARINÊS PEREIRA \\ BOMFIM $^{4}$, ANA ELIZABETE LOPES RIBEIRO ${ }^{4}$
}

\begin{abstract}
RESUMO - O presente estudo foi desenvolvido com o objetivo de avaliar a incidência e a severidade da malformação floral em diferentes cultivares de mangueira (Mangifera indica L.), em condições de clima semi-árido, no município de Santa Maria da Vitória, Estado da Bahia. O experimento foi conduzido no mês de julho de 2001, em um cultivo comercial formado por diversas cultivares divididas em talhões. Os tratamentos foram compostos por seis cultivares assim distribuídas: T1- Rosa; T2- Haden; T3- Bourbon; T4- Palmer; T5- Tommy Atkins; T6-Van Dyke. Nas condições em que o trabalho foi desenvolvido, os menores índices de incidência e severidade da malformação floral foram obtidos pela cultivar Rosa que não apresentou sintomas, seguida pela 'Bourbon'. A cultivar Haden apresentou os maiores índices da doença.
\end{abstract}

Termos para indexação: Fusarium subglutinans, Mangifera indica, manga, doenças.

\section{INCIDENCE AND SEVERITY OF MANGO FLOWER MALFORMATION IN SIX CULTIVARS}

ABSTRACT - The present work was developed with the objective to evaluate the incidence and the severity of mango flower malformation in different cultivars, in conditions of semi-arid region, in Santa Maria da Vitória, Bahia State, Brazil. The experiment was carried out in july, 2001, in a mango orchard composed of different cultivars. The used treatments cultivars were: T1- Rosa; T2- Haden; T3 Bourbon; T4- Palmer; T5- Tommy Atkins; T6Van Dyke. In the conditions that this work was carried out, the highest percentage of incidence and severity of flower malformation was gotten by Haden variety. Rosa and Bourbon cultivars presented minimum occurrence of the disease.

Index terms: Fusarium subglutinans, Mangifera indica, disease.

Tendo como agente etiológico o fungo Fusarium subglutinans, a malformação floral, conhecida popularmente como embonecamento, é uma doença que tem causado sérios problemas aos produtores de manga, pois inflorescências atingidas não produzem frutos ou os abortam precocemente. De acordo com Ribeiro (1997), o sintoma característico da malformação floral é a redução no comprimento do eixo primário e ramificações secundárias da panícula,o que confere à inflorescência um aspecto compacto.

O Fusarium subglutinans tem o ácaro das gemas da mangueira Aceria mangiferae Sayed como seu transmissor (Mora et al., 1998). Segundo Gonzalez et al.(1998), este acarino é um vetor muito eficiente ao transportar sobre seu corpo esporos do fungo e facilitar sua entrada ao alimentar-se de tecidos jovens.

No Brasil, constatou-se a ocorrência da malformação em várias áreas produtoras como: São Paulo, Minas Gerais, Pernambuco, Goiás e Bahia (Cunha et al., 1993). Porém, existe pouca informação relacionada às condições do clima que favorecem o desenvolvimento do fungo, bem como sobre a suscetibilidade das cultivares de mangueira à doença.

As cultivares predominantes no Brasil são aquelas de origem da Flórida - EUA, a maioria delas introduzidas em São Paulo, através do Instituto Agronômico de Campinas (IAC), na década de 70. São elas a 'Tommy Atkins', 'Keitt', 'Palmer', 'Haden'e 'Van Dyke' (Soares, 2000). Mas foi a partir de 1980, com a obtenção de informações sobre as cultivares americanas nas condições de São Paulo, que a 'Tommy Atkins' ganhou importância comercial. A partir daí, junto com a 'Keitt', têm sido as mais plantadas (Donadio,1996). Plantios extensivos e tecnificados no Nordeste, principalmente no Vale do São Francisco, a partir de 1980, também foram baseados na 'Tommy Atkins', substituindo antigas cultivares (Sampaio, 1989). Apesar de não predominar em cultivos comerciais, a cultivar Rosa destaca-se economicamente com a sua produção voltada basicamente para o mercado interno, onde é amplamente consumida.

Segundo Ribeiro (1989), no Brasil, a malformação varia conforme o ano e o local, com uma nítida diferença entre as cultivares, porém as diferenças não são consistentes. O autor ainda afirma que, nos pomares comerciais de São Paulo, os maiores danos da doença se concentram na 'Tommy Atkins' e, em menor grau, na 'Haden'. Soares (1994), citado por Donadio (1996), avaliou 19 cultivares em Bebedouro- SP, e constatou que as mais afetadas foram : Surpresa, Tommy Atkins, 14/51, Fascell, Van Dyke, Keitt e Torbet. As cultivares : Espada de Ouro, Pavão, Zill, Florigon, Parvin e Dixon foram consideradas mais tolerantes. Santos Filho (1992) cita que na Índia a cultivar Bhadauran é a única resistente. Schlosser (1971), citado por Piza Jr. \& Ribeiro (1996), considera a 'Langra' tolerante à malformação. De acordo com Ribeiro (1997), a incidência desta anomalia tem levado à erradicação de pomares, principalmente da 'Tommy Atkins', sendo que estudos genéticos realizados na Índia mostraram que a resistência a essa doença é conferida por genes recessivos, não havendo cultivares totalmente resistentes.

São José et al. (1999) realizaram um levantamento em diferentes áreas produtoras de manga do Estado da Bahia, para quantificar o percentual de incidência e severidade da malformação floral. Os resultados encontrados foram de $54 \%$ para a incidência e $17 \%$ para a severidade.

Considerando-se o fato de que a importância econômica da malformação floral pode variar de acordo com a suscetibilidade da cultivar, objetivou-se avaliar a incidência e a severidade da doença em diferentes cultivares de mangueira em condições de clima semi-árido, no município de Santa Maria da Vitória-BA.

O estudo foi desenvolvido no mês de julho de 2001, em um cultivo comercial de mangueira, com quatro anos de idade, formado por diversas cultivares isoladas em talhões, onde se determinaram os seguintes tratamentos: T1- Rosa; T2- Haden; T3- Bourbon; T4- Palmer; T5- Tommy Atkins; T6- Van Dyke.

Os tratamentos foram identificados dentro de cada talhão, onde as parcelas, formadas por cinco plantas, foram distribuídas aleatoriamente, em quatro repetições.

A incidência foi determinada através da observação e contagem das plantas com sintomas de malformação dentro de cada parcela, obtendo-se, assim, a porcentagem. Para avaliar a severidade, realizou-se

\footnotetext{
${ }^{1}$ (Trabalho 065/2002). Recebido: 15/04/02; Aceito para publicação: 07/02/03.

${ }^{2}$ Eng. Agrôn., Especialista, Universidade Estadual do Sudoeste da Bahia, Estrada do Bem Querer, Km 04, Caixa Postal 95, Vitória da Conquista-BA, CEP-45083-900. E-mail: nodias@terra.com.br

${ }^{3}$ Eng. Agrôn., Dr., Universidade Estadual do Sudoeste da Bahia, Curso de Agronomia, Estrada do Bem Querer, Km 04, Caixa Postal 95, Vitória da Conquista - Ba. CEP 45083-900, E-mail: Abelsj@uesb.br

${ }^{4}$ Discente do curso de Agronomia- Universidade Estadual do Sudoeste da Bahia
} 
a contagem das inflorescências doentes e sadias, individualmente em cada planta, calculando-se, desta forma, a porcentagem de inflorescências atacadas por planta.

Para a análise estatística dos dados, foi utilizada a transforma-

ção arc-sen $\sqrt{x / 100}$. As médias foram confrontadas, utilizando-se do teste de Tukey, a 5\% de probabilidade.

A presença da malformação floral foi constatada em cinco das cultivares estudadas. Apenas o tratamento 1, correspondente à 'Rosa', apresentou-se livre de qualquer sintoma característico da doença.

O tratamento 3 (Bourbon) apresentou, em média, a menor porcentagem de incidência, diferindo estatisticamente dos demais, que apresentaram a freqüência de plantas doentes muito alta, sendo que, para os tratamentos 2 (Haden) e 5 (Tommy Atkins), observaram-se os sintomas presentes na totalidade das plantas avaliadas (Tabela 1 ).

TABELA 1- Médias em porcentagem de incidência da malformação floral, em seis cultivares de mangueira. Santa Maria da Vitória-Ba, 2001

\begin{tabular}{lc}
\hline TRATAMENTOS & INCIDÊNCIA(\%) \\
\hline T2- Haden & $100 \mathrm{a}$ \\
T5- Tommy Atkins & $100 \mathrm{a}$ \\
T6- Van Dyke & $98,7 \mathrm{a}$ \\
T4- Palmer & $94,72 \mathrm{a}$ \\
T3- Bourbon & $55,52 \mathrm{~b}$ \\
T1- Rosa & $00 \mathrm{c}$ \\
CV(\%) & 14,727
\end{tabular}

Médias seguidas por letras iguais não diferem estatisticamente, pelo teste de Tukey, a $5 \%$ de probabilidade.

Apesar da alta incidência observada para os tratamentos 5; 6 e 4 (Tommy Atkins, Van Dyke e Palmer, respectivamente), as médias obtidas pelos mesmos quanto à severidade foram estatisticamente menores que as obtidas pelo tratamento 2, representado pela 'Haden', onde a doença, além de atingir nível máximo de incidência, apresentou porcentagem superior quanto à severidade (Tabela 2). Resultados de maior severidade para a 'Haden', nas condições estudadas, demonstram uma realidade diferente dos pomares de São Paulo, onde, segundo Ribeiro (1989), os maiores danos da malformação floral se concentram na 'Tommy Atkins' e, em bem menor grau, na 'Haden'. Estas diferenças ocorrem, provavelmente, devido à influência de vários fatores como: clima, época do ano, tratos culturais, etc. Ainda segundo Ribeiro (1989), no Brasil, a malformação varia conforme o ano e o local, com uma nítida diferença entre as cultivares, porém as diferenças não são consistentes.

TABELA 2-Médias em porcentagem de severidade da malformação floral, em seis cultivares de mangueira. Santa Maria da Vitória$\mathrm{Ba}, 2001$.

\begin{tabular}{lc}
\hline TRATAMENTOS & SEVERIDADE $(\%)$ \\
\hline T2- Haden & $79,47 \mathrm{a}$ \\
T4- Palmer & $21,15 \mathrm{~b}$ \\
T5- Tommy Atkins & $16,49 \mathrm{~b}$ \\
T6- Van Dyke & $8,13 \mathrm{bc}$ \\
T3- Bourbon & $1,52 \mathrm{~cd}$ \\
T6- Rosa & $00 \mathrm{~d}$ \\
CV $(\%)$ & 25,64
\end{tabular}

Médias seguidas por letras iguais não diferem estatisticamente, pelo teste de Tukey, a $5 \%$ de probabilidade.
Nas condições em que o presente trabalho foi desenvolvido, os melhores resultados foram obtidos pela cultivar Rosa, que não apresentou os sintomas da doença e, em segundo lugar, pela 'Bourbon', que além de ter apresentado a menor incidência entre os tratamentos, apresentou uma baixa porcentagem de severidade, que não diferiu significativamente da cultivar Rosa .

\section{REFERÊNCIAS BIBLIOGRÁFICAS}

CUNHA, M. M. da; COUTINHO, C. de C.; JUNQUEIRA, N. T. V.; FERREIRA, R. F. Manga para exportação: aspectos fitossanitários. Brasília: MAARA/FRUPEX,1993.103p. (Publicações Técnicas, 3).

DONADIO, L. C. Cultivares de mangueira. In: SÃO JOSÉ, A. R.; SOUZA, I. V. B.; MARTINS FILHO, J.; MORAIS, O. M. Manga: tecnologia de produção e mercado. Vitória da Conquista-BA: DFZ/UESB, 1998. p. 32-56.

GONZÁLEZ, H. H.; VALLE, P. de. ; JAVIER, J.M.; OTERO, G. C.; SANCHEZ M. R. Plagas del mango. In: TÉLIZ O. D. EI mango y su manejo integrado en Michoacan, Texcoco, México: GIIM, 1998. p. 13-17.

MORA, A.; VEGA,A.; TÉLIZ D.; GONZÁLES M.; JAVIER J. Enfermedades del mango. In: TÉLIZ O. D. EI mango y su manejo integrado en Michoacan, Texcoco, México: GIIM, 1998. p. 18-44.

PIZA Jr, C. T.; RIBEIRO, I. J. A. Principais moléstias da mangueira. In: SÃO JOSÉ, A. R.; SOUZA, I. V. B.; MARTINS FILHO, J.; MORAIS, O. M. Manga: tecnologia de produção e mercado. Vitória da Conquista-BA: DFZ/ UESB, 1998. p. 167-201.

RIBEIRO, A. J. Doenças da mangueira. In: KIMATI, H.; AMORIM, L.; BERGAMIN FILHO, A.; CAMARGO, L. E. A.; REZENDE, J. A. M. Manual de fitopatologia:doenças das plantas cultivadas. 3.ed.São Paulo: Agronômica Ceres, 1997. v. 2, p. $511-524$.

RIBEIRO, I.J.A . Controle de moléstias da mangueira. In: SIMPÓSIO SOBRE MANGICULTURA, 2., 1989, Jaboticabal. Anais... Jaboticabal:FCAV-UNESP, 1989. p.113-126.

SAMPAIO, J. M. M. Aspectos gerais da mangicultura no Nordeste. In: SIMPÓSIO SOBRE MANGICULTURA, 2., 1989, Jaboticabal. Anais... Jaboticabal:FCAV-UNESP, 1989. p.57-64.

SÃO JOSÉ, A. R.; SOUZA, S. E.; PIÑA, A. V.; ATAÍDE, E. M. Incidence and severity of mango flower malformation in Bahia state, Brazil. In: INTERNATIONALSYMPOSIUM OF MANGO, 60, 1999, Pattaya City, Thailand. Proceedings..., v.2, n.1, p.765-768

SOARES, N. B. Mangueira. In: MELETTI, L.M.M. Propagação de frutíferas tropicais. Guaíba: Agropecuária, 2000. p.178-187. 